\section{Periapical Status and Prevalence of Endodontic Treatment in Institutionalized Elderly}

Eduardo Hebling', Lorena Alves Coutinho', Caio Cézar Randi Ferraz², Fernanda Lopes Cunha', Dagmar de Paula Queluz ${ }^{1}$

\begin{abstract}
The aim of this study was to determine the prevalence and frequency of apical periodontitis and root fillings in 450 institutionalized Brazilian elderly. The teeth with apical periodontitis were assessed using the Periapical Index (PAI) score. A total of 942 teeth were evaluated in 98 subjects ( 57 females and 41 males) with mean age of 74 years. The observed frequency of total edentulous subjects was high (76\%) in this population. A total of 126 teeth showed root fillings, of these only $46(36.5 \%)$ were scored as having adequate quality. Apical periodontitis was found in 114 teeth (12.1\%) in 42 (42.9\%) subjects. 80 (70.2\%) inadequate root-filled teeth showed apical periodontitis. There was a significant correlation between the presence of periapical pathology and inadequate root-filled teeth. Inadequate root-filled teeth were associated with an increased prevalence of apical periodontitis in these subjects. This fact may result in increased endodontic retreatment needs for this population.
\end{abstract}

'Department of Community Dentistry, School of Dentistry of Piracicaba, UNICAMP - University of Campinas, Piracicaba, SP, Brazil ${ }^{2}$ Department of Restorative Dentistry, School of Dentistry of Piracicaba, UNICAMP - University of Campinas, Piracicaba, SP, Brazil

Correspondence: Prof. Dr. Eduardo Hebling, Caixa Postal 52, 13414903 Piracicaba, SP, Brasil. Tel: +55-19-2106-5209. e-mail: hebling@fop.unicamp.br

Key Words: apical periodontitis, elderly, Endodontics, epidemiology, radiology.

\section{Introduction}

The increase in the longevity of the world population and the success of preventive dentistry will lead to a growth of the expectation of maintenance of dentition in the elderly patients (1). This fact may result in an increase of the endodontic treatment needs in this population (2). Apical periodontitis (AP) is primarily a sequela to dental caries caused by infection of the root canal system (3). The aim of endodontic epidemiological survey has been described as gaining knowledge of the prevalence of AP and its determinants including treatment outcome in different populations evaluated by presence or absence of AP. Little epidemiological data on the endodontic and periapical status of the elderly have been gathered. These endodontic parameters are important to predict tooth survival and the future need for dental treatment (4). Specifically in Brazil, an analysis of the endodontic treatment needs in elderly population is not available to date. Tooth loss is highly prevalent in the Brazilian elderly population. In a previous study, edentulousness was observed in $74.9 \%$ of institutionalized Brazilian elderly (5).

Outcomes from cross-sectional epidemiological surveys showed evidences that older subjects have a lower number of remaining teeth and higher ratio of root-filled teeth (RFT) and AP in their teeth compared with younger adults (4). Longitudinal studies also confirmed these results demonstrated that, on average, the number of teeth decreased with age, but the number of RFT increased in studied elderly populations $(6,7)$. However, contrary to these cross-sectional and longitudinal studies, other longitudinal study in elderly women with follow-up of 24 years showed that the prevalence of AP did not increase with age, probably as a result of root canal treatment and extractions. This study also showed that the frequency of RFT and teeth with AP decreased over time for comparable age groups (8).

In different populations, several epidemiological studies have reported the frequency of AP to range from 1.4\% (9) to $8.0 \%$ (2), using the tooth as a unit. However, when subjects are used as the unit, the prevalence of AP can be as high as $70 \%$, and it increased with the age (9). High frequency of lesions associated with RFT has been also found, especially those related with inadequate endodontic treatments (2).

Thus, currently and in the future, more people will live longer and with more teeth in the oral cavity $(2,10)$. Actions and public policies for the prevention of oral diseases should be directed to the elderly population, aiming at the equity and equality of opportunities in the maintenance of their oral health and teeth (10). Data from endodontic epidemiological survey can contribute for development of these actions and policies (11).

Considering the importance of epidemiological investigations, the aim of this study was to determine both prevalence and frequency of AP and RFT in institutionalized elderly population.

\section{Material and Methods}

This cross-sectional study was approved by the institutional Ethics Committee (Protocol \#90/2010). 
The sample was selected from a population of 450 subjects living in two similar long-permanence institutions (LPI) for elderly people (community-dwelling elderly persons) at Piracicaba, SP, Brazil. Of the seven LPI of this city, these two institutions were selected because they provide a higher number of residents with socioeconomic and cultural characteristics similar to those of the general elderly population. The convenience sample was selected according to the following inclusions criteria: subjects aged above 60 years, functionally independent or partly dependent, showed no cognitive or systemic deficiency that could difficult the trial, with a minimum of 3 remaining teeth (excluding third molars), and that fill out the written informed consent. Elderly patients having less than 3 remaining teeth were excluded based on the mean of teeth present in institutionalized elderly found in previous study (12). The subjects were classified according to gender (male or female) and age (60-64; 65-74; 75-79; 80-84; 85-90; $>90$ years old).

All participants underwent a periapical radiographic survey in their present teeth. Care to biosafety was maintained during the survey. The radiographs were taken with X-ray unit (Eletronic 70x model spectrum, mobile ¿ column; Dabi Atlante, Ribeirão Preto, SP, Brazil), using the long-cone paralleling technique, setting of $70 \mathrm{kV}, 10$ $\mathrm{mA}$, a film-focus distance of $28 \mathrm{~cm}$ and ultra speed film (Ultra Speed; Eastman Kodak, Rochester, NY, USA), lead apron and thyroid shield. The radiographic films were standardized processed using an automatic roller-type processor (Gendex GXP Model; KaVo Dental Corporation, Gendex Dental Systems, Lake Zurich, IL, USA) according to the instructions of the manufacturer.

The following data were recorded on a structured form for each subject: a) number of teeth present; b) number and location of teeth without root fillings (untreated teeth) having identifiable periapical lesions; c) number and location of RF; d) number and location of RFT with identifiable periapical lesions. Teeth were classified as RFT if their canals had been filled with a radiopaque material. Toot filling quality was assessed according to the following criteria (13): a) satisfactory length/extension of root filling: filling material present in the root canal within 0-2 $\mathrm{mm}$ of the radiographic apex; b) unsatisfactory length/extension of root filling: filling material in the root canals more than $2 \mathrm{~mm}$ from the radiographic apex, extruded beyond the apical foramen, or present only in the pulp chamber.

The periapical status was assessed using the periapical index (PAI) score. Each score used in the PAI represents a step on an ordinal scale of registration of periapical inflammation: $1=$ normal periapical structures; $2=$ small changes in bone structure; $3=$ changes in bone structure with some mineral loss; $4=$ periodontitis with well defined radiolucent area; $5=$ severe periodontitis with exacerbating features. The periapical status of all teeth was assessed. The worst score of all roots were taken to represent the PAI score for multi-rooted teeth. PAl score greater than 2 (PAI $\geq 3$ ) was considered to be a sign of AP (14).

The radiographic film was assessed by one calibrated examiner in a darkened room, using an illuminated viewer box with $3.5 \times$ magnification while mounted in a cardboard slit to block off ambient light emanating from the viewer. The calibration process consisted of theory knowledge about PAl system, interpreting 100 radiographic images of teeth, some root filled and some not, during 4 sessions, totalizing $16 \mathrm{~h}$. After scoring the teeth, the results were compared with a "gold standard atlas" (14). The Cohen's Kappa test was used to determine the intraexaminer agreement. Intraexaminer agreement was evaluated by the repeat scoring of 40 randomly selected patients 2 months after the first examination. This intraexaminer agreement test produced a Cohen's $k$ of 0.79 (substantial agreement).

Raw data were entered into Excel ${ }^{\mathrm{TM}}$ (Microsoft Corporation, Redmond, WA, USA). The analyses were carried out using SAS software (SAS Institute Inc, Cary, NC, USA). The frequency of RFT was calculated, and the periapical status on all teeth and on the treated teeth was assessed. Chi-square and independent t-tests $(\alpha=5 \%)$ were used to examine associations between both prevalence and frequency of $A P$ in RFT and root filling pattern.

\section{Results}

The study population of 450 elderly showed $76 \%$ of edentulous ( $n=342)$ and $24 \%$ of dentate $(n=108)$ subjects. From this last group, 106 persons were located showing the criteria of inclusion for this study. During the development of the survey, 8 persons were excluding for got sick, unable or have died. The selected sample was compound by 98 old people, both genders (57 females; 41 males), with mean aging of 74 years (ranging to 60-94 years). No statistically significant differences were observed (unpaired t-test, $\mathrm{p}=0.9095)$ between the mean age of women $(78.0 \pm 7.9$ years) and men (77.8 \pm 7.1 years). The predominance of the female gender was superposed to the male gender. The largest concentration of people by age group was between 75-84 years of age (48\%), but there were no statistically significant differences when compared with the group of 65-74 years of age (Table 1).

Excluding the third molars, there were 1,326 lost teeth, representing $48.3 \%$ of total possible teeth. The mean number of the teeth per subject was 11.6. Of the 98 participating subjects, $48(49.0 \%)$ had at least one endodontically treated tooth. The periapical status of 942 teeth was evaluated. The mean number of periapical radiographs per person was 5.2 (range 3 to 14). There were 
126 teeth (13.4\%) with filling material in the root canals, indicating previous endodontic treatment. Of these, only 46 (36.5\%) were scored as adequate quality. AP was found in 114 teeth $(12.1 \%)$ in $42(42.9 \%)$ subjects. Of these, AP was diagnosed in $80(70.2 \%)$ inadequate RFT. There was a significant correlation between the presence of periapical pathology and inadequate root fillings $(p<0.05)$. AP was also diagnosed in 32 teeth (28.0\%) without root filling, showing no significant statistical correlation (Table 2). No significant differences between males and females were found for presence of AP, RFT and RFT with AP ( $p>0.05)$. The prevalence of AP between the age groups showed no statistically significant differences ( $p>0.05$ ). The frequency of AP and RFT with AP did not vary significantly with age ( $p>0.05$ ), but the 65-74 and 75-84-year-old groups had the highest frequencies.

The frequency of AP in inadequate RFT was $0.2 \%$ of the total of examined teeth, and $1.6 \%$ of total RFT. The frequency of inadequate RFT was $8.5 \%$ of total teeth, and $63.5 \%$ of total RFT. The frequency of AP in untreated teeth in this present study was $3.4 \%$. The prevalence of AP was $51.9 \%$. The prevalence of RFT was $49.4 \%$ (Table 3 ).

\section{Discussion}

This present cross-sectional study was the only one that

Table 1. Characteristics of the sample

\begin{tabular}{lll}
\hline Variable & $\mathrm{n}$ & $\%$ \\
\hline Institution & & \\
A & 74 & 75.5 \\
B & 24 & 24.5 \\
Gender & & \\
$\quad$ Female & 57 & 58 \\
$\quad$ Male & 41 & 42 \\
Age group (years) & & \\
$60-64$ & 6 & 6.1 \\
$65-74$ & 36 & 36.8 \\
$75-84$ & 47 & 48.0 \\
$85-90$ & 7 & 7.1 \\
$>90$ & 2 & 2.0 \\
Total & 98 & 100 \\
\hline
\end{tabular}

used sample of study including exclusively elderly patients to date. Studies with samples not exclusive but containing elderly patients showed data generalized to other groups of people with lower age range, making it difficult to compare the results. This fact highlights the importance of this present study and the need for further studies with similar specific samples of populations of elderly people in other regions and countries.

The studied subjects were elderly patients living in two

Table 3. Distribution of both prevalence and frequency of apical periodontitis (AP) and root-filled teeth (RFT), considering the total number of subjects, teeth, and root-filled teeth

\begin{tabular}{|c|c|}
\hline Variables & $\mathrm{n}$ \\
\hline \multicolumn{2}{|l|}{ Sample } \\
\hline Subjects (present teeth) & 98 (942) \\
\hline Range age (mean) & $60-94(74)$ \\
\hline \multicolumn{2}{|l|}{ Prevalence of AP } \\
\hline Subjects with $\geq 1$ (\%/total subjects) & $42(42.9)$ \\
\hline \multicolumn{2}{|l|}{ Prevalence of RFT } \\
\hline Subjects with $\geq 1$ (\%/total subjects) & $40(49.4)$ \\
\hline \multicolumn{2}{|l|}{ Frequency of AP } \\
\hline In all teeth (\%/total teeth) & $114(12.1)$ \\
\hline In RFT (\%/total RFT) & $82(65.1)$ \\
\hline Untreated teeth (\%/total teeth) & $32(3.4)$ \\
\hline \multicolumn{2}{|l|}{ Frequency of RFT } \\
\hline In all teeth (\%/total teeth) & $126(13.4)$ \\
\hline \multicolumn{2}{|l|}{ Adequate RFT } \\
\hline In all teeth (\%/total teeth) & $46(4.9)$ \\
\hline In all RF teeth (\%/total RFT) & $46(36.5)$ \\
\hline \multicolumn{2}{|l|}{ Inadequate RFT } \\
\hline In all teeth (\%/total teeth) & $80(8.5)$ \\
\hline In all RFT (\%/total RFT) & $80(63.5)$ \\
\hline \multicolumn{2}{|l|}{ Frequency of RFTwith AP } \\
\hline In all teeth (\%/total teeth) & $82(8.7)$ \\
\hline \multicolumn{2}{|l|}{ Adequate RFT } \\
\hline In all teeth (\%/total teeth) & $2(0.2)$ \\
\hline In all RFT (\%/total RFT) & $2(1.6)$ \\
\hline \multicolumn{2}{|l|}{ Inadequate RFT } \\
\hline In all teeth (\%/total teeth) & $80(8.5)$ \\
\hline In all RFT (\%/total RFT) & $80(63.5)$ \\
\hline
\end{tabular}

Table 2. Prevalence and frequency of apical periodontitis (AP) related to the quality of root filling in elderly population

\begin{tabular}{|c|c|c|c|c|c|c|}
\hline \multirow[b]{2}{*}{ Variable } & \multicolumn{2}{|c|}{ Prevalence of apical periodontitis } & \multicolumn{3}{|c|}{ Frequency of apical periodontitis } & \multirow[b]{2}{*}{$\mathrm{p}$ value } \\
\hline & $\begin{array}{c}\text { Subjects } \\
(\%)\end{array}$ & $\begin{array}{c}\text { Teeth } \\
(\%)\end{array}$ & $\begin{array}{l}\text { Untreated } \\
\text { teeth }(\%)\end{array}$ & $\begin{array}{c}\text { Adequate } \\
\text { RFT (\%) }\end{array}$ & $\begin{array}{c}\text { Inadequate } \\
\text { RFT (\%) }\end{array}$ & \\
\hline Apical periodontitis & $42(42.9)$ & $114(12.1)$ & $32(28.0)$ & $2(1.8)$ & $80(70.2)$ & 0.001 \\
\hline $\begin{array}{l}\text { No apical } \\
\text { periodontitis }\end{array}$ & $56(57.1)$ & $828(87.9)$ & $784(94.7)$ & $44(5.3)$ & $0(0.0)$ & \\
\hline Total & $98(100)$ & $942(100)$ & $816(86.6)$ & $46(4.9)$ & $80(8.5)$ & \\
\hline
\end{tabular}


large LPI for elderly people. Although following established inclusion criteria, this sample represented a convenience sample. Clearly, the sample of the present study does not represent a random sample of the elderly Brazilian population, and extrapolation of the results to the elderly population must be carried out with caution. However, the cohort reflected the characteristics of the current Brazilian dentate elderly population and there was no skewed recruitment from a socioeconomic perspective due to the inclusion of subjects from various socioeconomic classes (inclusion criteria for dwelling in the studied LPI). The lack of preventive and educational actions in the past makes the current elderly population show low prevalence of present teeth in the oral cavity. This fact could be observed in other elderly populations around the world, which showed the number of teeth decreased with age $(7,8)$. Of total possible teeth found in the present sample, $48.3 \%(n=1,326)$ were lost. The mean number of teeth persubject was 11.6, which is similar to other Brazilian study using institutionalized elderly sample (5). Thus, the results of this study may provide useful data to assess trends concerning the prevalence of AP and endodontic treatment in elderly population.

Another limitation of this and other studies using $\vec{z}$ similar methodology is that the evaluations were limited to radiographs, and no information about the time elapsed since endodontic treatment was available. It is commonly known that apical lesions limited to the cancellous bone usually pass undetected by conventional radiographic techniques. Moreover, the microbiologic conditions of the root canal and apex cannot be inferred on the basis of radiographic examinations alone (4). Another fact related to the time is relative to the type of epidemiologic study used in this present study. Cross-sectional studies do not include a time dimension. Consequently, results from these studies should not be misinterpreted as being absolute measures of treatment success or failure. Cross-sectional studies describe exposure (study variable of interest) and disease status at the time of the investigation. It is not possible in this type of study to decide whether the exposure preceded the disease or the disease preceded the exposure $(3,4)$.

Outcomes from longitudinal studies demonstrated the increase of the prevalence of RFT, AP and RFT with AP over the time $(9,15)$. However, a longitudinal study showed stabilization of the prevalence ratios of AP over an observation period of 5-10 years. It is tempting to suggest that one of the essential explanations for this fact may be that teeth with AP were more likely to be extracted in the past than today (16). A study assessing clinical decision-making approach demonstrated that few general practitioners decided to perform retreatment of RFT with a relatively small but clearly visible lesion, even though it was not expected to heal, whereas specialists in
Endodontics were more willing to perform retreatment if an AP lesion persisted (17). Both the lower proportion of extracted teeth and the tendency among practitioners to "wait and see" could be result in more teeth presenting with signs of AP. This fact could be more evident in elderly patients, although these patients showed a history of tooth loss rates higher than adults and young patients, affecting the comparison between groups (15).

A requirement for proper performance of epidemiological research is the use of defined criteria for the conditions under investigation including training and calibration of the investigators. The criteria should be: measurable; mutually exclusive; meaningful related to the condition under investigation (valid); reproducible; communicable (5). The PAI methodology (14) is an example of a set of criteria that fulfill these requirements. One of the main advantages of using a well-defined index system is to ensure inter-individual reproducibility and facilitate comparison between different investigations. The commonly applied success/failure judgment lacks this quality and, in addition, reliability and validity cannot be evaluated to the same extent (4).

Comparison between the results of the present study and the literature related to this subject showed some difficulties. The terms prevalence, incidence, and frequency were often confused, misused, and transposed. Prevalence is a frequently used epidemiological measure of how commonly a disease or condition occurs in a population. Prevalence measures how much of some disease or condition there is in a population at a particular point in time. The prevalence is calculated by dividing the number of persons with the disease or condition at a particular time point by the number of individuals examined. Prevalence is often expressed as a percentage, calculated by multiplying the ratio by 100 . The incidence of a disease is another epidemiological measure. Incidence measures the rate of occurrence of new cases of a disease or condition. Incidence is calculated as the number of new cases of a disease or condition in a specified time period (usually a year) divided by the size of the population under consideration who are initially disease free. The frequency of a disease estimates the ratio of this disease in a class. In cross-sectional studies, the prevalence (subject-level) and frequency (tooth-level) of AP could be estimated. The incidence of AP could be estimated only in longitudinal studies (4).

The lack of standardized criteria to assess the prevalence and the frequency of both AP and RFT in several published articles, establishing the correct level of measure unit (subject, tooth, root or root-filled tooth), resulted in difficulties in comparison of the outcomes between previous studies and the present one. Variations in sampling procedure, type of radiograph examined and 
inhomogeneous samples, especially regarding the age of participants, were other difficulties for comparisons.

No specific survey on the endodontic needs or the periapical heath status of Brazilian elderly population has been published at the time of writing this report. Only five studies were published using Brazilian population samples with subjects from different ages, including elderly subjects ( $\geq 60$ years) (18-22). Three of these studies $(19,21,22)$ used the PAI methodology to assess the prevalence of AP; one of these did not use the PAI methodology (20), and the other one neither used this methodology or described the age of the sample, thus it was discarded to comparison (18). In the Brazilian studies that used the PAI methodology, the prevalence of AP ranged from 67.5 (19) to 84.5\% (22) of total subjects, whereas in this present study was $51.9 \%$ (Table 3).

Only one Brazilian reported the prevalence of RFT, and it was equal to $83.3 \%$ of total subjects (22), whereas in the present study it was $49.4 \%$ of total subjects (Table 3 ).

Using the tooth as a unit, the frequency of AP in these studies ranged from 5.9 (19) to $12.9 \%$ (22) of total teeth, whereas in this present study was $12.1 \%$. The frequency of AP in RFT in these studies ranged from 38.0 (21) to 42.5\% (19), and it was $65.1 \%$ in this present study (Table 3 ).

In inverse correlation, the frequency of RF teeth with AP ranged from 4.7 (19) to $12.9 \%$ (22) of total teeth, whereas in this present study was $8.7 \%$ (Table 3 ). In addition to these Brazilian studies, the frequency of AP in inadequate $\mathrm{RF}$ teeth could be found in only one report (22) and was equal to $4.5 \%$ of total teeth, whereas in the present study was $8.5 \%$. Using the RF tooth as a unit, the frequency of AP in inadequate RF teeth ranged from 28.6 (21) to 30.9\% (22), whereas in the present study was 63.5\% (Table 3). There was a statistically significant correlation between the presence of AP and inadequate RF teeth (Table 2).

The quality assessment of the RF teeth in these Brazilian studies could be determined in only one study (22) and was equal to $4.8 \%$ of adequate RF teeth and $9.6 \%$ of inadequate $\mathrm{RF}$ teeth, respectively. Similar outcomes were found in the present study, which showed $4.9 \%$ of adequate RF teeth and $8.5 \%$ of inadequate RF teeth (Table 3 ).

In different countries, in the last years, reviewed epidemiological studies $(3,16,23-26)$ using sample including elderly subjects and periapical radiographic trial showed prevalence of AP ranging from 42.3 (24) to $84.5 \%$ (23) of the total sample. The frequency of AP in these studies ranged from 3.4 (24) to $12.9 \%$ (23) of the total studied teeth. The present study showed both high prevalence $(51.9 \%)$ and frequency of AP $(12.1 \%)$. The frequency of AP in RF teeth in these studies ranged from 40.0 (25) to $68.8 \%$ (24) of the total RFT, whereas in this present study was $65.1 \%$ (Table 3 ).
The majority of AP lesions seem to be located in teeth with previous root filling. Microbiological infection represents the etiology of AP and the incomplete root fillings probably aggravate the possibilities for such infections to persist or re-establish in these RFT (21). In a broader context, results from multivariate epidemiological studies indicated that previous endodontic treatment, regular dental care and caries experience appear as strong disease determinants. These facts indicate that the performed dental treatment is not able to effectively prevent or cure apical periodontitis, although the microbiological etiology and how to cope with microbial infection are well established (7).

In the studies that showed outcomes of untreated teeth with AP $(3,16,23-25)$, the frequency of AP ranged from 0.8 (24) to $7.1 \%$ (23) of the total studied teeth. In this present study, the frequency of AP in untreated teeth was 3.4\% (Table 3). In the studies that showed outcomes on the frequency of AP in inadequate RFT $(23,25)$, this frequency ranged from $3.4(25)$ to $4.5 \%$ (23) of the total studied teeth, and ranged from 16.8 (25) to $30.9 \%$ (23) of the total RFT, whereas in this present study was $8.5 \%$ of total teeth, and 63.5 of total RFT (Table 3 ). These results, in a broader context, demonstrated increased treatment needs for endodontic treatment in the elderly population. The endodontic treatment needs for these subjects including root filling and retreatment.

When extrapolating treatment needs one must, however, be aware of the differences between the terms "want," "demand," and "need" (4). Want is the individual's own assessment of his or her dental health. Demand denotes those wants that are ultimately turned into requests for professional care. Need, however, is an objective assessment defined by a professional intraoral and radiographic examination as performed in the present study. In general the (objective) treatment needs exceed the (subjective) demands of the patient. This holds especially true in elderly people. Even with this consideration in mind, one can speculate that the endodontic treatment need of the elderly population will grow due to the reduction of early tooth loss by the activities of preventive dentistry in the young and adult population. On the other hand, generally improved oral health might also result in a lower proportion of teeth needing endodontic treatment.

Age-related changes of the dental pulp complex and their relationship to systemic aging were well described, influencing the endodontic treatment in elderly patients (4). This fact together with the other changes and systemic diseases observed in the elderly intended that these subjects could be considered as patients who require special care. Brazil was one of the first countries to recognize the specialty of Geriatric Dentistry, specialty oriented to the specific treatment of this population group (10). The 
constant growing of the elderly population will certainly absorb more of the working capacity of the dental profession than we are currently willing to believe. With increased life expectancy and consequent longevity of the world population, more people will live longer and with more teeth in the oral cavity. Thus, the demand for dental treatment of elderly patients will probably increase. General practitioners as well as endodontists will need an expanded knowledge of the needs and the techniques for care of elderly patients. These facts collaborated with the implementation of actions and public policies for the prevention of oral diseases in the elderly population, aiming at the maintenance of their oral health and teeth.

In conclusion, based on the data of the present study, inadequate root filling was associated with an increased prevalence of AP in institutionalized elderly population. This fact may result in a greater demand for endodontic treatment in this population.

\section{Resumo}

0 objetivo deste estudo foi determinar a prevalência e a freqüência de periodontite apical e de tratamentos endodônticos em 450 idosos brasileiros institucionalizados. Os dentes com periodontite apical foram avaliados com uso do Índice Periapical (PAI). Um total de 942 dentes

$\vec{\tau}$ foram avaliados em 98 pacientes (57 mulheres; 41 homens), com média ¿ de idade de 74 anos. A freqüência observada do total de individuos desdentados foi alta (76\%) nesta população. 126 dentes apresentaram tratamento endodôntico, destes apenas $46(36,5 \%)$ foram classificados como de qualidade adequada. Periodontite apical foi encontrada em 114 dentes $(12,1 \%)$ em $42(42,9 \%)$ sujeitos. $80(70,2 \%)$ dentes com tratamento endodôntico inadequado apresentaram periodontite apical. Houve uma correlação significativa entre a presença de patologia periapical e dentes com tratamento endodôntico inadequado. Os dentes com tratamento endodôntico inadequado foram associados com uma maior prevalência de periodontite apical nestes indivíduos. Este fato pode resultar em aumento das necessidades de retratamento para esta população.

\section{References}

1. Müller $F$, Naharro $M$, Carlsson GE. What are the prevalence and incidence of tooth in the adult and elderly population in Europe? Clin Oral Impl Res 2007;18:2-14.

2. Imfeld TN. Prevalence and quality of endodontic treatment in an elderly urban population Switzerland. J Endod 1991;17:604-607.

3. Jiménez-Pinzón A, Segura-Egea JJ, Poyato-Ferrera M, Velasco-Ortega E, Ríos-Santos JV. Prevalence of apical periodontitis and frequency of root-filled teeth in an adult Spanish population. Int Endod J 2004;37:167-173.

4. Ericksen HM, Kirkevang LL, Petersson K. Endodontic epidemiology and treatment outcome: general considerations. Endod Topics 2002;2:1-9.

5. Ferreira RC, Magalhães CS, Moreira NA. Tooth loss, denture wearing and associated factors among an elderly institutionalized Brazilian population. Gerodontol 2008;25:168-178.

6. Frisk $F$, Hugoson $A$, Hakeberg M. Technical quality of root fillings and periapical status in root filled teeth in Jönköping, Sweden. Int Endod J 2008;41:958-968.
7. Eckerbom M, Anderssom JE, Magnusson T. A longitudinal study of changes in frequency and technical standard of endodontic treatment in a Swedish population. Endod Dent Traumatol 1989;5:27-31.

8. Petersson K. Endodontic status of mandibular premolars and molars in an adult Swedish population. A longitudinal study 1974-1985. Endod Dent Traumatol 1993;9:13-18.

9. Frisk F, Hakeberg M. A 24-year follow-up of root filled teeth and periapical health amongst middle aged and elderly women in Göteborg, Sweden. Int Endod J 2005;38:246-254.

10. Hebling E, Mugayar L, Dias PV. Geriatric dentistry: a new specialty in Brazil. Gerodontol 2007;24:177-180.

11. Kirkevang LL. Root canal treatment and apical periodontitis: what can be learned from observational studies? Endod Topics 2011;18:51-61.

12. Piuvezam G, de Lima KC. Factors associated with missing teeth in the Brazilian elderly institutionalised population. Gerodontol 2013;30:141149.

13. De Moor RJG, Hommez GMG, De Boever JG, Delmé KIM, Martens GEI. Periapical health related to the quality of root canal treatment in a Belgian population. Int Endod J 2000;33:113-120.

14. Ørstavik D, Kerekes K, Eriksen HM. The periapical index: a scoring system for radiographic assessment of apical periodontitis. Endod Dent Traumatol 1986;2:20-34.

15. Eckerbom M, Fygare L, Magnusson T. A 20-year follow-up study of endodontic variables and periapical status in a Swedish population. Int Endod J 2007:40:940-948.

16. Kirkevang LL, Vaeth $M$, Hörsted-Bindslev $P$, Wenzel A. Longitudinal study of periapical and endodontic status in a Danish population. Int Endod J 2006;39:100-107.

17. Kvist $\mathrm{T}$, Heden $\mathrm{G}$, Reit $\mathrm{C}$. Endodontic retreatment strategies used by general practitioners. Oral Surg Oral Med Oral Pathol Oral Radiol Endod 2004;97:502-507.

18. Siqueira JF Jr, Rôças IN, Alves FR, Campos LC. Periradicular status related to the quality of coronal restorations and root canal fillings in a Brazilian population. Oral Surg Oral Med Oral Pathol Oral Radiol Endod 2005;100:369-374.

19. Terças AG, Oliveira AEF, Lopes FF, Maia Filho EM. Radiographic study of the prevalence of apical periodontitis and endodontic treatment in the adult population of Sao Luis, MA, Brazil. J Appl Oral Sci 2006;14:183187.

20. Hollanda AC, de Alencar AH, Estrela CR, Bueno MR, Estrela C. Prevalence of endodontically treated teeth in a Brazilian adult population. Braz Dent J 2008;19:313-317.

21. Estrela C, Leles CR, Hollanda AC, Moura MS, Pécora JD. Prevalence and risk factors of apical periodontitis in endodontically treated teeth in a selected population of Brazilian adults. Braz Dent J 2008;19:34-39.

22. Marotta PS, Fontes TV, Armada L, Lima KC, Rôças IN, Siqueira Jr JF. Type 2 diabetes mellitus and the prevalence of apical periodontitis and endodontic treatment in an adult Brazilian population. J Endod 2012;38:297-300.

23. Kirkevang LL, Hörsted-Bindslev P, Ørstavik D, Wenzel A. Frequency and distribution of endodontically treated teeth and apical periodontitis in an urban Danish population. Int Endod J 2001;34:198-205.

24. Segura-Egea JJ, Jiménez-Pinzón A, Ríos-Santos JV, Velasco-Ortega $\mathrm{E}$, Cisneros-Cabello R, Poyato-Ferrera M. High prevalence of apical periodontitis amongst type 2 diabetic patients. Int Endod J 2005;38:564-569.

25. Tsuneishi M, Yamamoto T, Yamanaka R, Tamaki N, Sakamoto T, Tsuji K, et al.. Radiographic evaluation of periapical status and prevalence of endodontic treatment in an adult Japanese population. Oral Surg Oral Med Oral Pathol Oral Radiol Endod 2005;100:631-635.

Received October 17, 2013 Accepted March 17, 2014 